\title{
CASAS COMERCIAIS NO SÉCULO XX EM PANAMBI: SENSIBILIZANDO PARA O USO DE SACOLAS RETORNÁVEIS
}

\author{
WERHMANN, Temia (Coordenadora do MAHP), HEMPE, Cléa; \\ SCHEUER, Janete Finger (Professoras lotadas no MAHP).
}

\section{RESUMO}

Foi pensando nas mudanças que ocorreram a partir da segunda metade do século XX que o Museu e Arquivo Histórico Professor Hermann Wegermann - MAPH organizou o Projeto "Casas Comerciais em Panambi no Século XX". O Projeto envolveu os funcionários e professores que desempenham atividades no MAPH e contou com o apoio da Secretaria Municipal de Educação e Cultura. A programação fez parte da agenda de eventos permanentes do IBRAM, com o tema "Museus para Harmonia Social". Sabe-se que não há harmonia social sem que haja um "ambiente sustentável".

O MAHP ao desenvolver ações educativas leva em conta o seu acervo, promovendo a interação de diferentes públicos (escola, tanto do município, como da região), estabelecendo diálogo com os visitantes, considerando o Museu como espaço de construção do conhecimento. No final do século XIX e início do século XX, a ênfase na educação que marcava os museus americanos começou a se disseminar também pela Europa. Os Museus passaram a ser não só um lugar onde as pessoas têm um encontro com as conquistas passadas da humanidade, mas também com a realidade dos dias atuais. A partir da década de 1990, estes laços se estreitaram com o mercado, por meio de mecanismos destinados a promover o apoio e o patrocínio à cultura de empresas, bem como às leis de incentivo a cultura.

Os Museus, na atualidade, passaram a ser vistos e pensados de outras formas, ou seja, não sendo apenas um local de exposição de peças e sim, como afirma Lourenço, como um espaço de experimentação e de ação educativa, através do atendimento às necessidades do público local e dos visitantes da região. Entende-se, assim, por ação educativa no museu, fazendo uso das palavras de Silva, "as experimentações do sujeito para criar, construir e representar novos conhecimentos, aliado ao seu processo pessoal de desenvolvimento nestes contatos".

O Projeto teve como objetivo contribuir com as entidades e escolas parceiras, visando à formação de competências, mudanças de atitudes e procedimentos dos atores sociais (pais, alunos e comunidade em geral), que potencializem os objetivos de melhoria da qualidade de vida e de promoção do desenvolvimento sustentável, com vistas a um futuro próspero para as futuras gerações.

O Projeto foi desenvolvido entre 12 a 05 de junho de 2010, em consonância com a $8^{\text {a }}$ Semana Nacional de Museus e envolveu alunos do 3 ao 5 ano do Ensino Fundamental. Foi composto por uma série de atividades e teve como principal atrativo uma exposição temporária que reconstituiu um exemplo de casa comercial do século passado, a partir de alguns objetos do acervo do Museu e de móveis e objetos emprestados para esta ocasião.

Participaram das ações educativas e de sensibilização trinta e oito turmas, totalizando oitocentos alunos e quarenta e cinco professores (professores, coordenadores e intérprete de libras). Contou-se também com aproximadamente trezentos visitantes da comunidade panambiense e cidades próximas e os seguintes apoiadores: SMEC, Lions Clube, ARPA FIÚZA e UAB/Panambi. Para a confecção das sacolas teve-se o apoio financeiro do CMMA. A culminância 
do Projeto foi o lançamento das Sacolas Retornáveis no dia 5 de junho de 2010 - Dia Mundial do Meio Ambiente.

Palavras Chaves: Museu. Educação Ambiental. Sensibilização

\section{INTRODUÇÃO}

O tema da 8a Semana de Museus intitulada "Museus para Harmonia Social" desencadeou uma série de reflexões sobre quais atividades seriam desenvolvidas no Museu em Panambi, visando a Semana de Museus. Os meios de comunicação nos primeiros meses do ano foram repletos de notórios desastres climáticos, o que reflete claramente os nossos problemas ambientais. Como, então, viver em harmonia social se não se consegue viver em um ambiente sustentável, com um consumo consciente? De que forma conscientizar a população para uma reflexão sobre o meio ambiente rumo à sustentabilidade, envolvendo o Museu em uma ação educativa?

As reflexões a partir deste contexto resultaram na ideia do Projeto "Casas Comerciais em Panambi no Século XX". Para quem ainda nasceu no final do século XX ou já no século XXI é absolutamente normal fazer compras em grandes mercados, escolhendo entre diversas marcas de produtos, na sua maioria, previamente pesados e acondicionados em embalagens de plástico. $\mathrm{O}$ código de barras gravado nas embalagens e a frieza nas relações entre o consumidor e o mercado são típicos de momento atual e não há nenhum estranhamento com relação a isto por parte dos mais jovens.

Entretanto, muitos que nasceram em meados do século XX ou ainda antes disso, habituados às antigas "casas comerciais", lembram com nostalgia do contato direto com o dono do negócio, que tratava o freguês pelo nome enquanto o atendia. $O$ pagamento era realizado em espécie ou a partir da entrega de mercadorias trazidas pelo freguês, pois o comerciante, normalmente, revendia estes produtos trocados com colonos na cidade de Cruz Alta ou arredores. Armazém, bolicho, casa comercial são algumas definições para representar os locais de comércio no século XX.

Em 1949, o núcleo urbano de Panambi, conforme Fausel (1949), possuía doze casas comerciais, enquanto que no núcleo rural eram vinte e duas. As localidades eram praticamente autosuficientes, pois além das casas comerciais, havia ferrarias, serrarias, açougues, entre outros estabelecimentos.

As casas comerciais continham mercadorias variadas. Direcionou-se o olhar para a forma de armazenamento destes produtos. No começo do século XX era utilizado o papel ou cartucho de papel, pois não havia embalagens plásticas. Elas surgiram na década de 1950 e, aos poucos, foram se popularizando. Porém, as descobertas já haviam iniciado no século anterior. O papel orgânico se decompõe com facilidade, já o plástico ao contrário é bem mais demorado. Tem entre suas principais fontes naturais a celulose, extraída dos vegetais, o carbono e, sobretudo, o petróleo, o gás natural e seus derivados. Embora sejam mais duráveis e tenham um custo de produção menor, os plásticos trazem consequências negativas ao meio ambiente.

A produção de sacolas plásticas demanda extração e refino de petróleo que resulta em muitas emissões e impactos na flora e na fauna. Depois de usadas, muitas vezes são jogadas no meio ambiente causando a morte de animais, poluindo as águas, entupindo bueiros e causando 
problemas nos aterros, como a impermeabilização dos solos e o revestimento de material orgânico que, na ausência de oxigênio, em vez de biodegradar, apodrece, gerando metano. Cerca de 10\% do lixo é formado por sacolas plásticas. Elas precisam mais de três séculos para se decompor. Em todo o mundo são produzidos quinhentos bilhões de unidades a cada ano (www.planeta sustentável).

Para concretização do Projeto "Casas Comerciais em Panambi no Século XX" foi realizado um levantamento junto à comunidade sobre móveis utilizados em casas comerciais que existiam em Panambi no século XX. Combinou-se então o empréstimo dos móveis com o objetivo de resgatar a história em Panambi referente às Casas Comerciais, oportunizando a divulgação deste Patrimônio Imaterial transmitido de geração em geração, promovendo um sentimento de identidade e respeito à diversidade cultural.

Também foi realizado levantamento de objetos que fazem parte do acervo do MAHP, pois esse tem a função de divulgar o seu acervo e promover a produção de conhecimento relacionando o objeto com seu valor histórico e a conjuntura nacional e internacional. Foram realizadas leituras sugeridas pelo IBRAM sobre o tema Museus para Harmonia Social, sobre ação educativa e trabalho de divulgação para a elaboração do Projeto "Casas Comerciais em Panambi no Século XX".

O objetivo geral do Projeto consistiu em divulgar a $8^{a}$ Semana do Museu, que teve como Título "Museus para Harmonia Social" e proporcionar atividades diversificadas aos alunos das diversas escolas, levando em consideração o tema da Semana de Museus e as principais características da harmonia social que são: o diálogo, a tolerância, a coexistência e desenvolvimento, que são baseadas no pluralismo, na diversidade, na competição, na criatividade e na sustentabilidade, entre outros.

Os objetivos específicos foram: proporcionar ao público alvo interação com a réplica da casa comercial, resgatando a história do processo de comercialização, industrialização e consequências para o meio ambiente; reconhecer o processo de imigração, percebendo o contexto econômico, político, religioso e social envolvido; coletar fotos e informações de casas comerciais que existiam em Panambi; buscar parcerias para confecção de sacolas ecológicas a fim de que fosse realizada uma Campanha quanto ao uso das mesmas; produzir frases e um mascote ou logomarca para ser impressa nas sacolas ecológicas retornáveis; promover palestras a fim de contextualizar a realidade do século XX e o momento atual, para que cada um possa conscientizarse e fazer a sua parte para termos um meio ambiente onde haja sustentabilidade; produzir histórias em quadrinhos, vídeos, programa de rádio/TV ou brinquedos a partir de fotos de casas comerciais em Panambi - século XX e outros materiais coletados.

A aplicação do Projeto, tem a finalidade de desenvolver processos educativos permanentes e continuados a partir de um enfoque dialético, humanista e construtivista, juntamente com as entidades e escolas parceiras, visando à formação de competências, mudanças de atitudes e procedimentos dos atores sociais (pais, alunos e comunidade em geral), que potencializem os objetivos de melhoria da qualidade de vida e de promoção do desenvolvimento sustentável, com vistas um futuro próspero para as futuras gerações. 


\subsection{Referencial Teórico}

Os primeiros museus públicos, como instituição, surgiram nos séculos XVII e XVIII, como consequência do crescente interesse pela cultura e pelas ciências.

No final do século XIX e início do século XX, a ênfase na educação que marcava os museus americanos começou a se disseminar também pela Europa. Os Museus passaram a ser não só um lugar onde as pessoas têm um encontro com as conquistas passadas da humanidade, mas também com a realidade dos dias atuais.

A partir da década de 90 , estes estreitam os laços com o mercado por meio de mecanismos destinados a promover o apoio e o patrocínio à cultura de empresas, bem como às leis de incentivo a cultura. Os Museus na atualidade passaram a ser visto e pensados de outras formas, ou seja, não sendo apenas um local de exposição de peças e sim como afirma Lourenço, são vistos como um espaço de experimentação e de ação educativa, através de atendimento às necessidades do público local e dos visitantes da região. Entende-se, assim, por ação educativa no museu, fazendo uso das palavras de Silva, "as experimentações do sujeito para criar, construir e representar novos conhecimentos, aliado ao seu processo pessoal de desenvolvimento nestes contatos".

Esse processo, a qualquer momento, pode ser revisto, reelaborado e modificado para favorecer uma interação social significativa do público com o espaço, pois a visita ao museu é uma experiência social e cultural, uma forma de compartilhar o saber no espaço público.

Vigotsky (1995), o grande pensador sobre processos psicológicos, relata que tudo que é tipicamente humano se origina da vida em sociedade. A criança nasce em um mundo humano, começa a sua vida em meio a objetos e fenômenos criados pelas gerações que a precederam e vai se apropriando destes, conforme se relaciona socialmente. Sendo assim, o Projeto teve como um dos focos, despertar nos alunos a consciência de que o excesso de plástico, que, em geral, acaba sendo descartado de maneira inadequada na natureza, é prejudicial ao Meio Ambiente.

O MAHP, ao desenvolver estas ações educativa levou em conta o seu acervo, promovendo a interação de diferentes públicos (escola, tanto do município, como da região), estabelecendo diálogo com os visitantes, considerando o Museu como espaço de construção do conhecimento.

Segundo Cabral (2011) "os estudantes constroem seus próprios significados e fazem sentido de acordo com o seu próprio modo a partir das oportunidades de aprendizagem que experimentam". A autora também afirma que cabe ao educador oferecer experiências apropriadas de aprendizagem, onde o conhecimento do estudante pode ser explorado, aumentado e testado.

\section{METODOLOGIA}

Para concretizar o Projeto utilizou-se da interação com o grupo de alunos, buscando a compreensão e a construção conjunta dos conceitos diversos relacionados à temática "Casas Comerciais do Século XX em Panambi", a partir da experiência dos seus componentes e do aporte teórico apresentado, isto é, vídeos, textos, palestras, motivando-os para a reflexão e construção conjunta de novos saberes.

A simulação vivenciada na prática, na Réplica da Casa Comercial visou estudos sobre imigração, comercialização, sustentabilidade, entre outros temas. Gerou análise e discussão nos 
pequenos grupos, debruçando-se sobre o vivido para extrair sentidos e indicadores para novas ações.

Ao retornar as escolas, os alunos produziram trabalhos (história em quadrinhos, logomarcas, cartazes, frases, textos...) e enviaram ao MAHP. A frase e logomarca selecionada foram estampadas nas sacolas retornáveis, as quais foram distribuídas na comunidade.

\section{RESULTADOS E DISCUSSÕES}

O Projeto desenvolveu-se entre 12 de abril e 05 de junho de 2010, em consonância com a 8a Semana Nacional de Museus. Envolveu alunos do 3으 ao 5을 ano do Ensino Fundamental. Participaram das ações educativas e de sensibilização trinta e oito turmas, totalizando oitocentos alunos e quarenta e cinco professores (professores, coordenadores e intérprete de libras). Contouse também com aproximadamente trezwentos visitantes da comunidade local e da região próxima.

O Projeto consistiu em dez etapas. As quatro primeiras foram enviadas por e-mail e disponibilizadas no blog do MAHP, no endereço eletrônico: http://mahp-panambi.blogspot.com e tiveram a finalidade, inicial, de analisar e comparar a evolução do comércio e da indústria e suas consequências. A seguir as etapas do projeto:

Etapa I - Elaboração de dois vídeos sobre os temas: "Casas Comerciais em Panambi no Século XX" e "Mercado em Panambi no século XXI". O primeiro vídeo foi elaborado a partir de filmagens na própria casa comercial organizada e com fotos coletadas durante as pesquisas e, 0 segundo vídeo, foi a partir de fotos e filmagem de um dos mercados de Panambi, focando o uso dos plásticos. Estes vídeos organizados pelos diversos profissionais do Museu tiveram como finalidade provocar o diálogo com os alunos sobre as mudanças ocorridas na passagem do século XX para o XXI.

Etapa II - Elaboração de uma história em quadrinhos, a fim de servir de ferramenta para o trabalho do surgimento do plástico. Também foram sugeridos sites de pesquisa, bem como a provocação do desejo de pesquisar a história com os avós sobre as mudanças anteriormente citadas e a visão sobre as mesmas.

Etapa III - Levantamento da legislação sobre a proibição do uso de sacolas plásticas no Brasil e em outros países.

Etapa IV - Elaboração de dois vídeos: um sobre o surgimento do lixo e o outro baseado na história do "Flautista de Hamelin" dos Irmãos Grimm, que desencadeou um diálogo sobre a nossa postura diante dos problemas causados pelo homem ao meio ambiente.

\section{Visita a Réplica da Casa Comercial do Século XX em Panambi - RS}

Na quinta etapa ocorreram visitas na "Réplica da Casa Comercial do Século XX", que foram agendadas com antecedência pelas diversas escolas. Também houve participação das comunidades local e regional, as quais também puderam interagir na Casa Comercial.

Etapa $V$ - A visitação à Réplica da Casa Comercial em Panambi no Século XX, pelo público alvo e demais visitantes local e regional teve como objetivo reviver a memória de nossos antepassados nos aspectos sociais, econômicos e políticos e divulgar a cultura de um determinado período. 
As visitas interativas à Exposição da Casa Comercial dos alunos foram agendadas por e-mail ou por telefone.

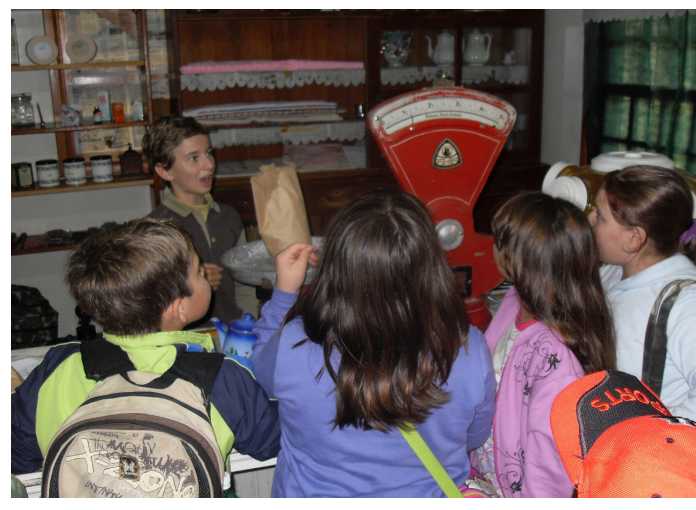

Figuras 1 e 2 - Alunos interagindo na Réplica da Casa Comercial do Século XX

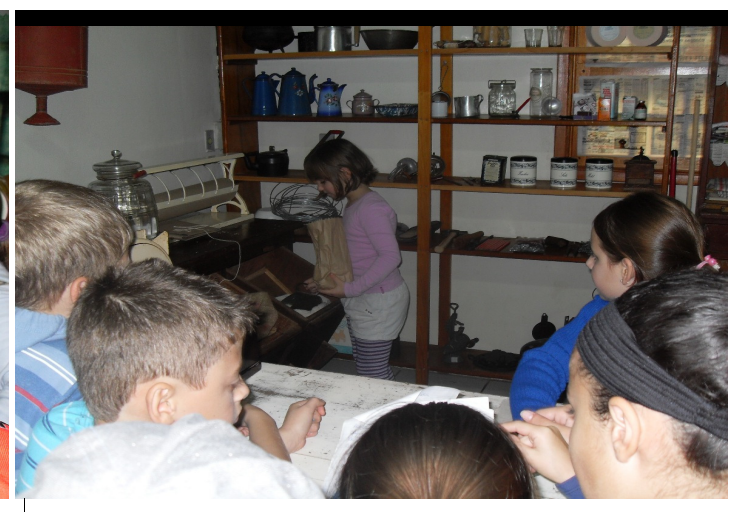

Divididos em grupos de 10 alunos, recebiam modelos de cédulas de cruzeiros (moeda vigente entre 1970 e 1986), simulando a seguinte situação: eram imigrantes chegando à Panambi pela Estação Belizário, no século passado, com a missão de se instalarem numa propriedade rural, sendo que a bagagem estava retida na alfândega e chegaria somente no terceiro dia após a instalação na propriedade. Enquanto aguardavam a chegada da bagagem realizavam as compras na casa comercial antes de seguirem para a propriedade.

Entre os produtos disponíveis para a simulação da compra, os alunos encontraram feijão, arroz e farinha, todos eles expostos na chamada tulha. Também encontraram uma série de outros objetos que costumavam fazer parte das casas comerciais no século passado: panelas, lampiões, talheres, copos, pentes, baldes, medicamentos (olina, infalivina), talco pompom, bolacha, banha, canjica, elástico, tecidos, balas, pirulitos, sorvete seco, merengue, bebidas, entre outros.

Os produtos em exposição receberam rótulos antigos, tendo como base alguns modelos arquivados no MAHP. Procurou-se também adaptar as embalagens, usando o mínimo possível de plástico, o qual passou a ser usado principalmente a partir da segunda metade do século passado e, hoje em dia, acondiciona a maioria dos produtos.

Durante a simulação, os alunos discutiam entre si quais produtos seriam necessários e conferiam se o dinheiro era suficiente para a aquisição dos pretendidos. O papel do comerciante também era desempenhado por um dos alunos. Pagavam as compras realizadas com o valor recebido e para finalizar, era realizada uma discussão sobre os produtos adquiridos em relação à quantidade e necessidade para sobrevivência e quais seriam supérfluos,

Etapa VI - As Palestras realizadas para alunos foram um complemento das atividades práticas e de pesquisas realizadas no decorrer do Projeto. Foram abordados dois temas para a sustentabilidade: "A alimentação através dos tempos", a qual foi ministrada por uma nutricionista e "Os resíduos sólidos, no caso os plásticos", proferida por um engenheiro agrônomo.

Etapa VII - Produções de trabalhos pelos alunos que visitaram a Exposição Casas Comerciais do Século XX

Etapa VIII - Criação de uma logomarca e uma frase. Esta atividade consistiu na criação de mascote ou logomarca e frase para estampar na sacola retornável. Para isso, houve trabalho prévio de conscientização frente à sustentabilidade do meio ambiente. A criação do mascote e da 
frase sobre vida sustentável aconteceu a partir da leitura e discussão de textos e pesquisas realizadas na escola no transcorrer do Projeto. Cada Escola participante selecionou uma frase e um mascote para enviar ao MAHP.

Etapa IX - Seleção da logomarca e frase: As equipes vencedoras da logomarca e da frase foram da Escola Municipal de Ensino Fundamental 21 de Abril, localizada na Linha Rincão Fundo zona rural do município de Panambi-RS. A frase escolhida foi "A vida do mundo está em nossas mãos. Você decide!"

Etapa $X$ - Culminância do Projeto aconteceu no dia 5 de junho, Dia Mundial do Meio Ambiente. Neste dia, o MAHP fez o lançamento da sacola retornável. Paraa confecção das sacolas teve-se o apoio financeiro do Conselho Municipal do Meio Ambiente e do Lions Clube Panambi. O Projeto também contou com o apoio das seguintes entidades: Secretaria Municipal de Educação e Cultura, Lions Clube Panambi, ARPA FIÚZA e Universidade Aberta do Brasil /Polo Presencial UFSM.

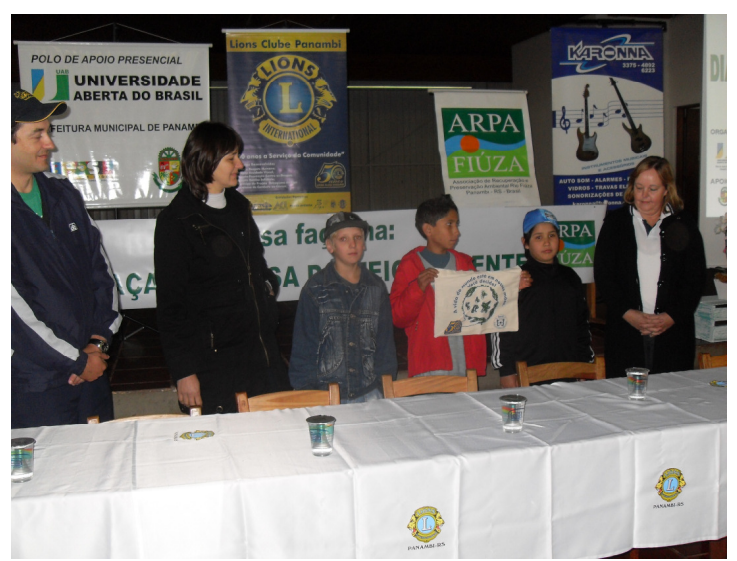

Figura 3 - llustra o momento do lançamento da sacola retornável

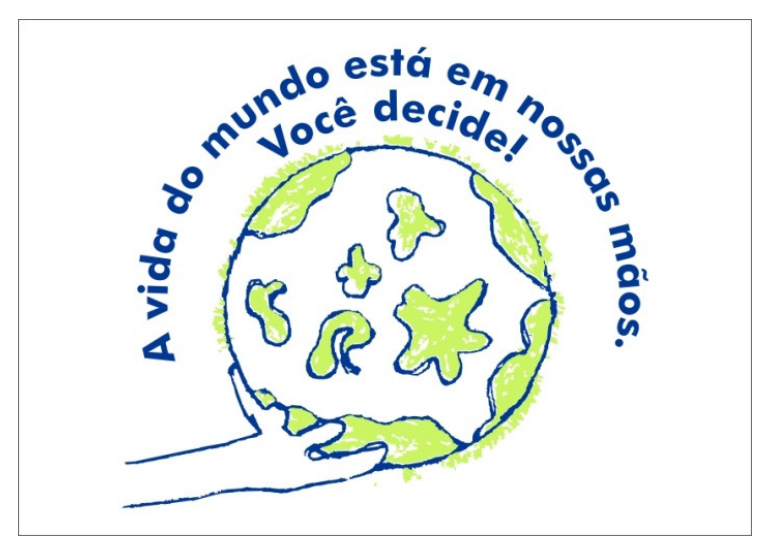

Figura 4 - Logomarca e a frase selecionada para a sacola retornável

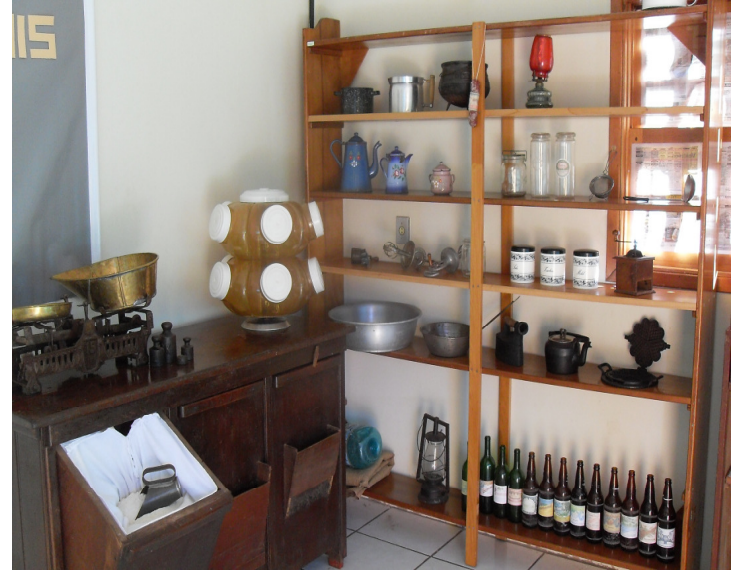

Figura 5 - Imagem Interna da Réplica da Casa Comercial do Século XX

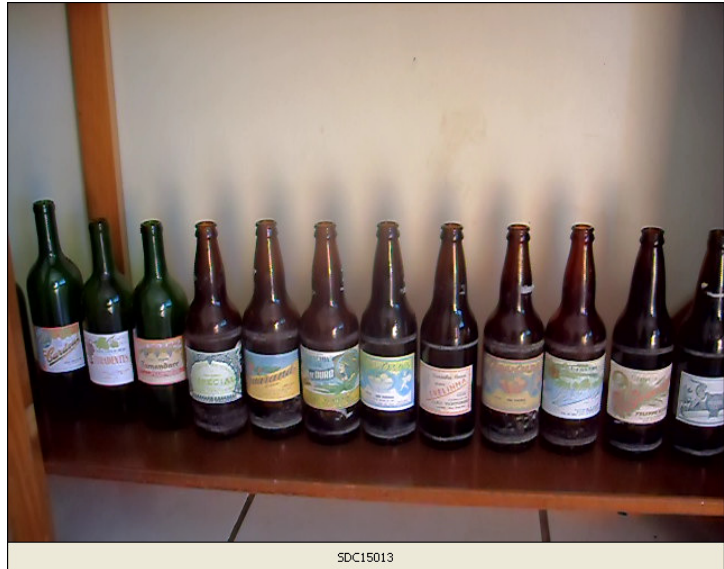

Figura 6 - Imagem Interna da Réplica da Casa Comercial do Século XX 


\section{CONCLUSÃO}

Ao encerrar as atividades propostas, realizou-se a avaliação do Projeto, que indicou que os objetivos propostos foram alcançados, pois os alunos e a comunidade participaram nas atividades propostas e ao mesmo tempo tiveram a oportunidade de viver ou reviver memórias de outros tempos, desencadeando um sentimento de identidade, contribuindo para promover o respeito à diversidade e a produção de conhecimentos relacionando diferentes aprendizagens em tempos diversos, através da interação na Réplica da Casa Comercial. Conhecimento sobre o avanço da tecnologia, suas conseqüências e qual é o nosso compromisso com a natureza, também foram objetivos alcançados.

Foi muito gratificante ver o envolvimento dos alunos desde a simulação da viagem de navio (imigrantes de meados do século XX), de trem e de carroça, o entusiasmo ao conhecer a Réplica da Casa Comercial, o planejamento das compras e o diálogo sobre as compras realizadas. Outro fato importante foi que muitas crianças retornaram trazendo os pais e amigos e queriam repetir a experiência. Entende-se que toda essa vivência e interação tornaram o trabalho de sensibilização sobre sustentabilidade mais significativo e dialógico, levantando hipóteses sobre o desafio dessa realidade e procurando soluções.

Conclui-se que o desenvolvimento desse Projeto atingiu considerável grupo de alunos, professores e comunidade em geral. Espera-se que estes sejam multiplicadores de práticas ambientais e que o MAHP tenha cumprido seu papel conforme definição DEMU/IPHAN/Minc 2004 "As instituições museológicas são compreendidas como práticas sociais colocadas a serviço da sociedade e de seu desenvolvimento e comprometidas com a gestão democrática e participativa". Com esta atividade o MAHP foi agraciado pelo segundo ano consecutivo com o Prêmio Nacional Darci Ribeiro. No ano de 2010 ficou em primeiro lugar e neste ano de 2011, classificou em segundo lugar. O prêmio refere-se as ações educativas, as quais envolvem alunos e suas respectivas escolas.Este artigo corresponde apenas uma mostra do trabalho que está sendo realizado no Museu Arquivo Histórico Professor Hermann Wegermann - MAHP.

\section{REFERÊNCIAS}

CABRAL, Magaly. Curso Ação Educativa em Museus, set de 2011.

FAUSEL, Erich. Cinquentenário de Panambi.1889-1949.

LOURENÇO, Maria Cecília. Museus acolhem o moderno. São Paulo: Edusp. 1999.

SILVA, Margarida Brandina Pantaleão. Museu e ação pedagógica: uma parceria de sucesso. Graduada em Desenho e Plástica - Licenciatura Plena; especialista em Arte, Teorias e Métodos; Mestre em Artes Visuais, docente da Faculdade de Artes e Comunicação da Universidade de Passo Fundo. Disponível em: <http://www.revistamuseu.com.br/artigos/art .asp?id=8948>. Acesso em: abr de 2011. 
Monografias Ambientais

(e-ISSN: 2236-1308)

REMOANFSM

VYGOTSKY, Lev. S. Obras Completas. vol. 5. La Habana: Editorial Pueblo Y Educacion, 1995.

Vídeos elaborados pela Equipe do MAHP. Disponibilizados em: $<$ http://mahppanambi.blogspot.com.>. Acesso em: set.2011.

Textos elaborados pela Equipe do MAHP. Disponibilizados em:<http://mahppanambi.blogspot.com.>. Acesso em: set.2011. 